\title{
Public Views on Policies Involving Nudges
}

William Hagman, David Andersson, Daniel Västfjäll and Gustav Tinghög

The self-archived postprint version of this journal article is available at Linköping University Institutional Repository (DiVA):

http:// urn.kb.se/ resolve?urn=urn:nbn:se:liu:diva- 119071

N.B.: When citing this work, cite the original publication. The original publication is available at www.springerlink.com:

Hagman, W., Andersson, D., Västfjäll, D., Tinghög, G., (2015), Public Views on Policies Involving Nudges, Review of Philosophy and Psychology, 6(3), 439-453. https:/ / doi.org/ 10.1007/ s13164-015-0263-2

Original publication available at:

https:/ doi.org/ 10.1007/ s13164-015-0263-2

Copyright: Springer Verlag (Germany)

http:// www.springerlink.com/?MUD=MP 


\title{
Public views on policies involving nudges *
}

\author{
William Hagman $^{1}$, David Andersson², Daniel Västfjäll1,3, Gustav Tinghög ${ }^{2,4}$
}

\section{Cite this article as:}

(Published in Review of Philosophy and Psychology)

Hagman, W., Andersson, D., Västfjäll, D. \& G.Tinghög., Rev.Phil.Psych. (2015) 6:

439. https://doi.org/10.1007/s13164-015-0263-2

\begin{abstract}
When should nudging be deemed as permissible and when should it be deemed as intrusive to individuals' freedom of choice? Should all types of nudges be judged the same? To date the debate concerning these issues has largely proceeded without much input from the general public. The main objective of this study is to elicit public views on the use of nudges in policy. In particular we investigate attitudes toward two broad categories of nudges that we label pro-self (i.e. focusing on private welfare) and pro-social (i.e. focusing on social welfare) nudges. In addition we explore how individual differences in thinking and feeling influence attitudes toward nudges. General population samples in Sweden and the United States ( $\mathrm{n}=$ 952) were presented with vignettes describing nudge-policies and rated acceptability and intrusiveness on freedom of choice. To test for individual differences, measures on cultural cognition and analytical thinking were included. The results show that attitudes toward nudge-policies were more positive in Sweden than United States, but the level of stated support was generally high in both countries. Somewhat paradoxically a majority of the respondents perceived the presented nudge interventions as intrusive to freedom of choice. Nudge-polices classified as pro-social had a significantly lower acceptance rate compared to pro-self nudges $(\mathrm{p}<.0001)$. Individuals with a more individualistic worldview were less likely to perceive nudges as acceptable, while individuals more prone to analytical thinking were less likely to perceive nudges as intrusive to freedom of choice. To conclude, our findings suggest that the notion of "one-nudge- fits-all" is not tenable. Recognizing this is an important aspect both for successfully implementing nudges as well as nuancing nudge theory.
\end{abstract}

Keywords: Nudge; Behavioral economics; Behavioral policy; libertarian paternalism; Paternalism

Correspondence: gustav.tinghog@liu.se

\footnotetext{
*We thank Paul Slovic, Lina Koppel and two anonymous reviewers for valuable comments on a previous version of the manuscript. Financial support by the Ragnar Söderberg Foundation and the Swedish Research Council (VR) is gratefully acknowledged

${ }^{1}$ Department of Behavioural Sciences and Learning, Linköping University, SE-581 83 Linköping, Sweden.

${ }^{2}$ Division of Economics, Department for Management and Engineering, Linköping University, SE-581 83 Linköping, Sweden.

${ }^{3}$ Decision Research, 1201 Oak Street, Suite 200, Eugene, Oregon 97401, USA.

${ }^{4}$ The National Center for Priority Setting in Health Care, Department of Medical and Health Sciences, Linköping University, SE-581 83 Linköping, Sweden.
} 


\section{Introduction}

Following the influential book by Thaler and Sunstein (2008), nudges have taken a prominent position in both academic and policy debates. When should nudging be deemed as permissible and when should it be deemed as intrusive to individuals' freedom of choice? Should all types of nudges be judged the same? To date this debate has largely proceeded without much input from the general public. Public attitudes toward nudge interventions are likely to be a key barrier/facilitator for successful policy implementations in this area. Thus, knowledge on public perception of nudge interventions is central for the field. This article aims to fill this knowledge gap by presenting policy scenarios, involving measures to change behavior across key policy areas, and elicit views on (i) acceptability and (ii) intrusiveness to freedom of choice. In particular we investigate public attitudes toward two broad categories of nudges that we label pro-self and pro-social nudges in samples of the general public in Sweden and the United States. In addition, the aim here is to examine how individual differences in "thinking and feeling” influence attitudes toward policies involving nudges.

Although some studies have surveyed related topics no previous study has, to our knowledge, explicitly explored acceptability toward nudge-policies and the extent to which nudge-policies are perceived as intrusive to freedom of choice. The most closely related studies are the studies conducted by Felsen et al. (2013) and Branson et al. (2011). By using contrastive vignettes, involving nudges that targeted either conscious or subconscious processes, Felsen et al (2013) found that individuals prefer nudges that target conscious thinking. However, this study explored only relative acceptability between two types of nudges and not general acceptability toward nudges which is the focus in this study. Branson et al. (2011) surveyed acceptability for generic state interventions across cultures and found relatively high levels of stated support for government involvement in behavior change across countries. In addition, and relevant for this study, they found that Swedish respondents were more acceptive of state intervention on behavior compared to US respondents. Thus, we predict that Swedish respondents will be more positively inclined toward nudge-policies in comparison to American respondents.

\section{Separating pro-social nudges from pro-self nudges}

The standard definition of a nudge as presented by Thaler and Sunstein (2008) is that a nudge: 
Is any aspect of the choice architecture that alters people's behavior in a predictable way without forbidding any options or significantly changing their economic incentives. To count as a mere nudge, the intervention must be easy and cheap to avoid. (p.6)

Placing healthy food upfront and at eye level in the cafeteria while placing snacks and less healthy food alternatives behind the counter exemplifies a nudge intervention aiming to make people eat less unhealthy food. Another prominent example used to describe nudging is the "save more tomorrow program" where a substantial increase in money transfer to retirement savings is instituted as the default rule, so that individuals are more likely to make choices about retirement savings in line with their long-term interests (Thaler and Benartzi 2004) ${ }^{1}$. Common for these traditional cases of nudging is that they involve choice architecture (i.e the way in which choices are presented) that is supposed to help individuals steer away from irrational behavior (or bounded rationality) which decreases their long-term wellbeing. We call this pro-self nudges. These pro-self nudges fit nicely into the paradigm of libertarian paternalism, which aims to nudge individuals to act in accordance with their best interests but still allows individuals to disregard the nudge at minimal or no cost.

The basic structure of a pro-self nudge (e.g. the cafeteria example) can be described as a scenario where an individual can choose between option A (a healthy snack) and option B (an unhealthy snack). Assuming rational behavior, it is typically profit maximizing in the long run to choose the healthy snack as a default ${ }^{2}$. Indeed many individuals with unhealthy habits are willing to pay third parties to help them make better decisions. Thus, with regards to pro-self nudges irrational behavior will cause a situation where current-self incurs high costs on future-self due to insufficient willpower ${ }^{3}$. Consequently pro-self nudges seek to counterbalance irrational behavior in order to maximize the overall good for an individual.

In the endeavor of bringing ideas about nudges into public policy there has been a shifted focus toward using nudges to increase prosocial behavior, thus primarily serving society at large as opposed to the individual. Making it easier for homeowners to recycle (i.e. green nudges) in order to achieve environmental goals is one example of this type of nudge. The use

\footnotetext{
${ }^{1}$ In contrast, banning or taxing junk food would not qualify as a nudge according to the definition made by Thaler and Sunstein (2008) because it implies forbidding or making a choice more expensive.

${ }^{2}$ It should of course be noted that not all unhealthy choices are caused by irrational behavior. However, many of the choices where individuals fail to stick to the plan that they previously have deemed optimal are unlikely to promote the overall welfare of the individual. See e.g. Thaler and Sunstein (2008p.7-9) for further discussion. ${ }^{3}$ There may be other types of pro-self nudges which do not concern weakness of will as the main cause of irrationality, e.g. nudges designed to fix overconfidence (see Bovens (2009) for further discussion). However here we focus on irrationality due to weakness of will.
} 
of default rules where people have to opt-out of giving money to charitable causes is another example. This category of nudges is epistemologically different from pro-self nudges since they aim to nudge individuals away from what according to neoclassical economic theory would be labeled rational behavior in order to avoid Tragedy of the Commons (Hardin 1968). We call this pro-social nudges. These pro-social nudges, however, do not fit into the paradigm of libertarian paternalism since it always is in the individuals' best interest not to contribute to the common good. Thus this category does not nudge individuals to act in accordance to their best interest, assuming that this is to maximize private welfare.

The basic structure of a pro-social nudge could be described as a scenario in which an individual can choose between option A (e.g., recycle) and option B (not recycle). Assuming rational behavior, it is always profit maximizing for the individual to free ride and choose not to recycle (disregarding possible benefits that stem from social signaling and/or warm glow). Thus, with regards to prosocial nudges, rational behavior will lead to a scenario where no one contributes to the overall good. Consequently pro-social nudges aim to counterbalance rational profit maximizing behavior in order to avoid overuse or under-provision to Public Goods.

When discussing when and why nudging is acceptable or not in public policy it is necessary to clearly separate these two categories of nudges since pro-social nudges focus on discouraging rational profit maximizing behavior while pro-self nudges encourage it. This clearly has implication for the normative debate but possibly also for the public support related to policies involving nudges. In this paper we categorize commonly discussed nudgepolicies as either pro-self or pro-social and explore if general attitudes toward these two broad categories differ in systematic ways. We predict that pro-social nudge-policies will be judged as less acceptable and more intrusive to individuals' freedom of choice compared to pro-self nudge-policies.

\section{Thinking and feeling in nudges}

Research in psychology and behavioral economics have, for a long time, recognized that people do not have stable values that they consult when making decisions (see e.g. Slovic 1995). Instead, they use whatever information they have available at the moment of making a decision - thereby constructing their preferences on the spot. This idea is the core basis of nudge theory; by changing how, and what, information is being presented (i.e. made 
accessible and salient) to individuals at the moment of making a decision, behavioral choices can be systematically changed (choice architecture; Thaler and Sunstein 2008; Sunstein 2014).

Some scholars, like Hausman and Welch (2010) have suggested that a defining characteristic of a nudge is that it plays on individuals intuitive thinking. In his most recent book, Why Nudge? The Politics of Libertarian Paternalism, Cass Sunstein (2014) rejects this view. Instead he suggests that nudges can either be targeted at System 1 "intuitive processing" or System 2 "analytical processing”. Examples of nudges that work on System 1 processing include the mentioned cafeteria re-design example. System 2 nudges include fact-driven education campaigns and active decision making - requiring people to engage their deliberative System 2 reasoning capabilities. However, educational campaigns can also target System 1 by focusing on fear and other emotions.

While most research to date has focused on the information presentation aspect of choice architecture, preference construction is also highly dependent on individual differences such as worldviews/values and preferences for intuitive vs. analytical thinking (Amir and Lobel 2008). For instance, research on decision-making and risk perception has shown that individual differences in intuitive vs. analytical thinking (i.e. cognitive reflection) systematically influence attitudes and behaviors (see e.g Slovic 1995; Frederick 2005; Kemmelmeier 2009). Moreover, individuals with individualistic worldviews (as opposed to a communitarian worldview) have been shown to have lower risk perceptions of factors such as climate change compared to individuals with more communitarian worldview (Kahan 2006; Kahan et al. 2010; Peters and Slovic 1996). Therefore, a second goal of the present research was to explore to what extent individual differences in worldview and intuitive vs. analytical thinking (system 1/system 2 thinking; Kahneman 2011) influence attitudes toward nudgepolicies.

Dan Kahan (2006), the creator of Cultural Cognition World View Scale, posits that people with a more pronounced individualistic worldview should be increasingly resistant to external control and thus be less accepting of policies that can be seen as an infringement of autonomy. Following this line of reasoning we predict that people with a more pronounced individualistic worldview are less likely to accept nudge-policies and more likely to perceive them as intrusive to freedom of choice compared to people with a more pronounced communitarian worldview. 
It is less straightforward to make predictions about the influence of individual differences in analytical thinking vs. intuitive thinking on attitudes toward nudge-policies. If nudges are primarily aimed at System 1 processing, which scholars like Hausman and Welch argue, then intuitive thinking individuals are likely to be more affected by nudges in their decision making. Still, this does not provide a clear rationale for predicting that individuals who rely more on intuitive thinking should be more or less accepting of nudges. For example, given that intuitive thinking individuals are likely to be influenced by nudges more frequently, they may also increasingly view nudges as an infringement on their autonomy. However, it is also possible that individuals who rely more on intuitions view nudges as a way to enhance autonomy by increasing the likelihood that choices are made in alignment with long-term interests. Analogously, individuals who rely more on analytical thinking may be less likely to view them as an infringement on autonomy because they are less likely to be influenced by nudges. They may also be less helped by nudges because they have set preferences and therefore view nudges more as mere manipulations on their deliberately set preferences.

\section{Method}

We carried out two separate data collections: one in Sweden and the other in the United States. In total, 952 subjects participated in the study which was conducted as a web-survey. In particular 514 subjects were recruited in Sweden (52.5\% Females; Mean age 51.3) and 438 subjects in USA (55.5\% Females; Mean age 44.3). In Sweden, data was collected in collaboration with CMA Research, and subjects were drawn from a sample of the general adult population previously included in their subject pool. In the United States, data was collected at Decision Research in Eugene Oregon and subjects were drawn from a sample of the adult US population included in the subject pool at Decision Research. It should be noted that both samples have a higher level of education compared to what would be a representative sample in respective country. Participants received a small monetary compensation, contingent on time spent to complete the survey. Instructions and design were identical across countries, but the instructions were translated into Swedish for the data collection in Sweden. Given that subjects were people who had already signed up to be included in the subject pool at CMA Research and Decision Research, response rates were high. In United States invitations to participate were sent out to 575 individuals and had a response rate of 76.2\%. In Sweden, we paid CMA Research a fee to collect 500 observations. Thus, invitations to participate were sent out to a large number of individuals, but the web 
survey was closed when the number of participants reached 514.

All subjects were presented with the same eight vignettes, but in random order. Each vignette presented a common case of nudging (e.g. opt in/opt out, affective images) in a specific policy area. The nudge scenarios were chosen to represent key policy areas and to include the most common type of nudge interventions (Marteau et al 2011; Thaler and Sunstein 2008). All policy scenarios are shown in Box 1. Policy scenarios 1-4 were classified a priori as prosocial and policy scenarios 5-8 were classified as pro-self according to described criteria. Following each scenario respondents were asked: (i) "Do you find the described policy acceptable?” and (ii) "To what extent do you think that the described policy restricts the individual's freedom of choice?”. To explore if the a priori classification of pro-social and pro-self nudge-policies corresponded to the respondents' perception two questions related to perceived benefits were included after each scenario: (iii) "Do you think, in general, that the described policy has positive effects for the individual?” and (iv) “Do you think, in general, that the described policy has positive effects for the society at large?”. Responses on all four questions were given on a four-point Likert scale ranging from 1 (not at al) to 4 (very much). ${ }^{4}$

\section{Box 1: Policy-scenarios presented in the experiment}

\section{Nudge-policies categorized as pro-social}

\section{1. "Organ donation"}

There is currently a lack of organ donors in many countries. In some places, to become an organ donor the individual has to make an active choice and register as an organ donor with the appropriate authority. If no choice is registered, the individual is assumed to be unwilling to donate in event of an accident (so called Opt-In). In previous surveys most people report that they are willing to be an organ donor but have not registered.

One way to increase the number of organ donors could be to automatically enroll people as organ donors unless otherwise specified (so called Opt-Out). In other words, it is up to the individual to register at the appropriate authority if they are unwilling to donate their organs in the event of an accident. The aim with this intervention (Opt-Out) is to increase the number of organ donors.

\section{2. "Climate compensation"}

Carbon dioxide emissions in connection with flying have a negative effect on the environment. To compensate for this, there is usually a voluntary fee that travelers can add to the final price. The money from this fee goes to projects to reduce emissions of carbon

\footnotetext{
${ }^{4}$ To facilitate understanding of the logistic regression output (Pedhazur1997), acceptability and intrusiveness were recoded into binary variables corresponding to acceptable/not acceptable and intrusive/not intrusive respectively. Similar results were however found when conducting the analyses with continuous dependent variables.
} 
dioxide to a corresponding level of the emission caused by the flight. To increase the number of travelers that choose to pay the climate compensation fee, it can automatically be added to the final price. Then, if a traveler does not want to pay the fee, the traveler instead has to make an active choice not to pay the fee (also known as Opt-Out). The idea with this intervention (Opt-Out) is to increase the number of travelers that compensate for climate.

\section{3. "Energy consumption"}

Most households today are over consuming energy, which leads to a waste of resources both for the household and society. Therefore energy companies that succeed in decreasing the average energy consumption among households receive government subsidies. To motivate households to lower energy consumption, an energy company attached some complementary information to the energy bill. The information added contained a comparison of energy consumption between the customer's household and other households in the neighborhood.

If the costumer's energy consumption was lower than the neighbors', a happy smiley face was shown on the bill. However, if the customer's energy consumption was higher than the neighbors', a sad face was shown. The idea with this intervention is that the feedback that these faces give will have a positive effect on the energy consumption of the households.

4. "Avoiding tax evasion"

Many countries have a problem with their citizens not paying taxes, which costs society a considerable amount of money. Some countries have therefore started to send out information to the taxpayers with the encouraging message "To pay your taxes is the right thing to do". The idea with this intervention is to give tax evaders a bad conscience and therefore increase their motivation to pay their taxes.

\section{Nudge-policies categorized as pro-self}

\section{1. "Smoking cessation"}

To many people it is difficult to stop smoking. To help these people there is a voluntary program where the amount of money the participant usually spends on cigarettes during a week is withdrawn from his/hers personal account into a savings account where the participants can observe the amount but not withdraw it.

During a period of six months, the participant undergoes testing to see if (s)he has been smoking. If the participant passes all tests the money is paid back to the participant. However if the testing shows that the participant has been smoking the money is donated to charity. The idea with this intervention is to increase the motivation among participants who are trying to quit smoking.

2. "Smoking discouragement"

Smoking often leads to addiction and has a negative effect on the health of the individual. To more clearly show the negative effects of smoking, many countries have started to add deterrent pictures on the cigarette packages. These images display damaged organs that can be a consequence of long term smoking. The idea with this intervention is to discourage people to start smoking and motivate people that are smokers to quit.

\section{3. "Cafeteria re-design"}

Overconsumption of calorie rich food can lead to a deteriorating health. In an attempt to get their employees to eat healthier, a company rearranged its cafeteria. Healthy food was placed at eye-level and easily available for the visitors of the cafeteria. Unhealthy food, such as 
candy or snacks was placed behind the counter to make it less visible and accessible for the visitors in the cafeteria. The idea with this intervention is to encourage the consumption of healthier alternatives to improve the health of the employees.

4. "Food labeling"

It can be difficult to tell which food products that are healthy and which are not, therefore a food chain started to label their products with stickers which look similar to a green and red stoplight or traffic signal. Healthy food, which is rich in minerals, vitamins, and has a low amount of fat and sugar, is marked with a green tag. Unhealthy food, which is rich in fat and sugar and has a low amount for minerals and vitamins, receives a red tag. The idea with this intervention is to make it easier to make healthy choices.

To explore if individual differences in thinking and feeling influence attitudes toward the presented nudge-policies we included the short versions of the Cultural Cognition Worldview Group scale (Kahan 2014) and the Rational-Experiential Inventory scale (Norris et al. 1998). These scales were added at the end of the survey.

The short version of the Cultural Cognition Worldview Group scale (CCWVG) is a 6-item measure that indicates if individuals are more or less predisposed toward an individualistic or communitarian worldview. For example, one of the statements with which respondents were asked to agree or disagree was: The government interferes far too much in our everyday lives. Responses were made on a four-point Likert scale ranging from 1 (strongly disagree) to 4 (strongly agree. A high score indicates a more individualistic worldview, whereas a low score indicates a more communitarian worldview. In United States responses were made on sixpoint Likert scale (1=strongly disagree, $6=$ strongly agree). This difference in response format between countries was because data on CCWVG at Decision Research in United States had been collected on occasions prior to the administration of the present survey. In order to allow for comparison between samples the CCWVG values were Z-scored before running regression analysis.

The Rational-Experiential Inventory scale (REI) is a 10-item measure designed to assess preferences for information processing. In the present research, we used only the rationality subscale, which is designed specifically to measure individual's preferences for using analytic thinking. For example, one of the statement with which respondents are asked to agree or disagree with is: I prefer complex problems to simple problems. Responses were made on a scale 1-4 (1=strongly disagree 4=strongly agree). Thus a high score indicates a stronger preference for analytical thinking. 


\section{Results}

\section{Public attitudes toward nudge interventions}

Table 1 presents results for the survey regarding general attitudes toward the presented nudgepolicies. Acceptability toward the presented nudge-policies was generally high, ranging from $54.0 \%$ (of respondents) for the least supported nudge-policy to $85.5 \%$ for the most supported. The rate of acceptance was generally higher in Sweden (72.7\%) compared to the United States $(66.1 \%)(\mathrm{t}(930)=4.03, \mathrm{p}<.0001)$. This difference between Sweden and United States is in accordance with the study by Branson et al. (2011), who found higher level of acceptability for state intervention on behavior in Sweden compared to the United States. The nudge-policy that was viewed as acceptable by most respondents in both Sweden and United States was the use of red and green warning signals in order to promote consumption of healthier food, i.e. “Food labeling” (86.9\% in Sweden and 83.8\% in the United States). The nudge-policy deemed as acceptable by the smallest fraction in the Swedish sample was the use of financial incentives to increase motivation to stop smoking, i.e. "Smoking cessation". Still a majority of the respondents (58.4\%) judged this as an acceptable nudge-policy. In the US sample the least supported nudge-policy was the use of an Opt-Out intervention in order to increase the number of organ donors, which was deemed acceptable by $42.9 \%$ of the respondents.

As shown in Table 1, a large proportion of respondents viewed the presented nudge-policies as intrusive to freedom of choice. Given the high level of acceptance toward the presented nudge-policies this might be seen as paradoxical. In line with the findings on judged acceptance, however, respondents from the United States were significantly more prone to judge nudge-policies as intrusive compared to Swedish respondents (Sweden 55.9\% and the United States 63.5\%, $\mathrm{t}(930)=4.08, \mathrm{p}<.0001)$. In Sweden the nudge-policy that was viewed as intrusive by the largest fraction of respondents (78.9\%) was the scenario focusing on the Opt-Out intervention in order to increase the number of organ donors. This nudge-policy was also viewed as intrusive by the largest fraction of the US sample (86.7\%). The nudge-policy deemed as intrusive by the lowest fraction of respondents (30.9\%) in the Swedish sample was the use of an encouraging message to decrease tax evasion, i.e. “Avoiding tax evasion”. In the United States, the use of red and green warning signals in order to promote consumption of healthier food (i.e. "Food labeling”) was viewed as intrusive by the lowest fraction of respondents (43.1\%). 
Table 1. Public attitudes on policies involving nudge-policies

\begin{tabular}{|c|c|c|c|c|c|c|c|c|c|}
\hline & \multirow[t]{2}{*}{$\begin{array}{l}\text { Categorization } \\
\text { of described } \\
\text { scenario Pro- } \\
\text { social/Pro-self }\end{array}$} & \multicolumn{2}{|c|}{$\begin{array}{l}\text { Ranking of societal vs } \\
\text { individual benefits } \\
\text { according to } \\
\text { respondents (mean } \\
\text { difference }{ }^{\mathrm{a}} \text { ) }\end{array}$} & \multicolumn{3}{|c|}{$\begin{array}{c}\text { Share of respondents } \\
\text { who judge the described } \\
\text { nudge-policy acceptable }\end{array}$} & \multicolumn{3}{|c|}{$\begin{array}{c}\text { Share of respondents who } \\
\text { judge the described nudge- } \\
\text { policy intrusive to } \\
\text { individuals freedom of } \\
\text { choice }\end{array}$} \\
\hline & & Sweden & USA & Sweden & USA & Total & Sweden & USA & Total \\
\hline Organ donation & Pro-social & $1(0.69)$ & $1(0.62)$ & $63.3 \%$ & $42.9 \%$ & $54.1 \%$ & $78.9 \%$ & $86.7 \%$ & $82.4 \%$ \\
\hline Climate compensation & Pro-social & $2(0.63)$ & $2(0.40)$ & $60.7 \%$ & $45.7 \%$ & $54.0 \%$ & $70.1 \%$ & $85.7 \%$ & $77.2 \%$ \\
\hline Avoiding tax evasion & Pro-social & $3(0.51)$ & $3(0.36)$ & $81.5 \%$ & $80.0 \%$ & $80.8 \%$ & $30.9 \%$ & $44.8 \%$ & $37.1 \%$ \\
\hline Energy consumption & Pro-social & $4(0.22)$ & $4(0.11)$ & $66.4 \%$ & $67.1 \%$ & $66.7 \%$ & $59.6 \%$ & $54.5 \%$ & $57.3 \%$ \\
\hline Smoking cessation & Pro-self & $5(0.17)$ & $6(0.04)$ & $58.4 \%$ & $60.5 \%$ & $59.3 \%$ & $67.8 \%$ & $73.1 \%$ & $70.2 \%$ \\
\hline Smoking discouragement & Pro-self & $6(0.13)$ & $5(0.10)$ & $81.6 \%$ & $72.6 \%$ & $77.6 \%$ & $41.2 \%$ & $51.4 \%$ & $45.8 \%$ \\
\hline Cafeteria & Pro-self & $7(0.08)$ & $8(-0.12)$ & $82.6 \%$ & $76.4 \%$ & $79.8 \%$ & $62.7 \%$ & $68.6 \%$ & $65.3 \%$ \\
\hline Food labeling & Pro-self & $8(-0.03)$ & $7(-0.05)$ & $86.9 \%$ & $83.8 \%$ & $85.5 \%$ & $36.1 \%$ & $43.1 \%$ & $39.3 \%$ \\
\hline All nudge-policies & & & & $72.7 \%$ & $66.1 \%$ & $69.7 \%$ & $55.9 \%$ & $63.5 \%$ & $59.3 \%$ \\
\hline
\end{tabular}

In order to test if the a priori classification of pro-social and pro-self nudge-policies corresponded to the respondents' perception, we subtracted the mean value of the perceived benefit for the individual from the mean value of the perceived benefit for society for each nudge-policy. The nudge-policies were then ranked from 1 to 8 based on the mean difference. Thus, a higher rank in Table 1 indicates that benefits for society increasingly exceed the benefits for the individual by the respondents according to the view of the respondents. When comparing mean difference in perceived societal gain and perceived individual gain for nudge-policies labeled as pro-social or pro-self, this difference was significantly higher for pro-social nudges in both countries. (Sweden, paired t-test difference $=0.5161, t(511)=20.64$, $\mathrm{p}<.0001$; the United States, paired t-test difference $=0.3744, \mathrm{t}(419)=15.35, \mathrm{p}<.0001)$. Thus, the normative classification of nudge-policies as pro-social or pro-self corresponded roughly to respondents’ perception of where benefits from particular nudges mostly accrue.

Figures 1a and 1b show the general level of acceptance and intrusiveness to individuals' freedom of choice for nudge-policies classified as pro-social and pro-self. When pooling responses across samples, rate of acceptance was $11.7 \%$ lower for nudge-policies classified as pro-social compared with nudge-policies classified as pro-self (paired t-test difference $=$ 11.7\%, $\mathrm{t}(931)=-12.58, \mathrm{p}<.0001)$. As shown in Figure 1b, pro-social nudges were significantly more often perceived as intrusive to freedom of choice compared with pro-self nudges across both samples (paired t-test difference $=8.3 \%, \mathrm{t}(931)=8.86, \mathrm{p}<.0001$ ). In addition we tested if these differences in attitude toward pro-social and pro-self nudges remained when using the respondents’ perception concerning where benefits mostly accrue, to classify nudges as pro- 
social or pro-self. In line with the previous results, this analysis showed that nudge-policies perceived as more pro-social by the individual were significantly less likely to be perceived as acceptable (difference in rate $=-0.1471, \mathrm{t}(386)=-5.86, \mathrm{p}<.0001$ ), and significantly more likely to be perceived as intrusive (difference in rate $=0.1155, \mathrm{t}(386)=4.54, \mathrm{p}<.0001$ ).

Figure 1. Public attitudes on policies involving nudge-policies: Comparing Pro-social and Pro-self

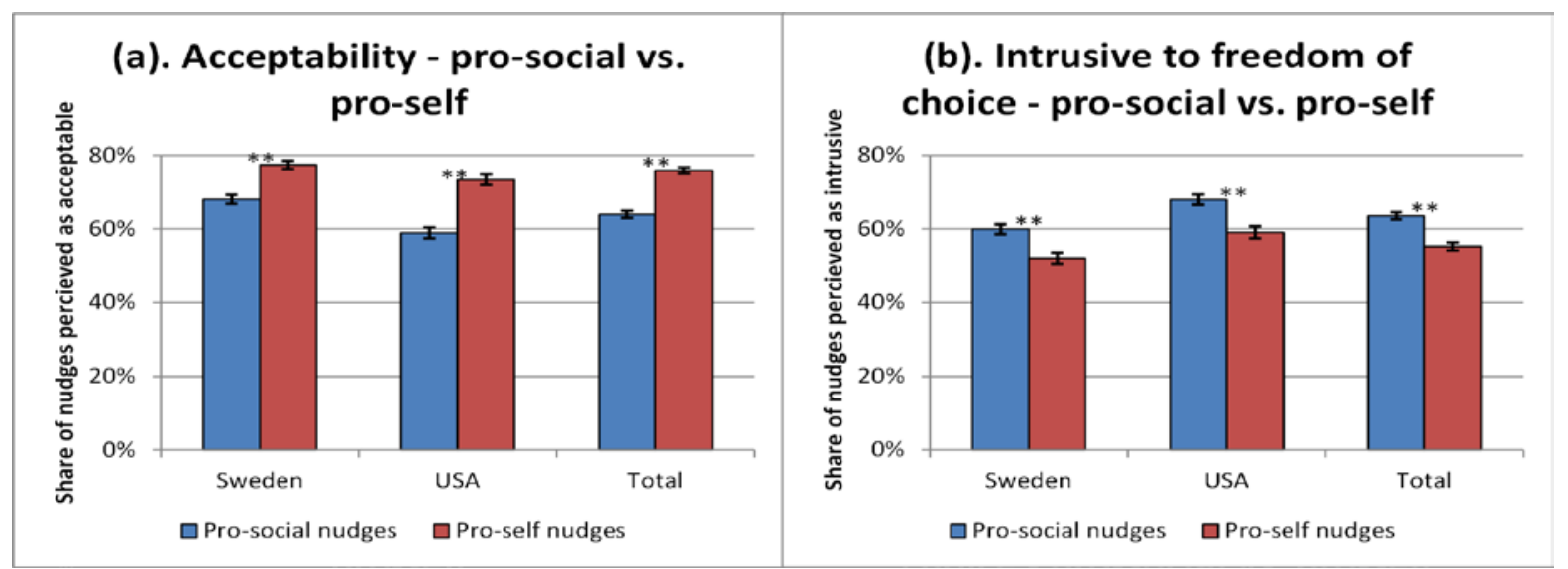

t-test; ${ }^{*} \mathrm{p}<.05,{ }^{* *} \mathrm{p}<.001$

Organ donation, Climate compensation, Avoiding tax evasion and Energy consumption are the nudge-policies that are categorized as Prosocial. Pro-self nudges-policies are Smoking cessation, Smoking discouragement, Cafeteria and Food labeling.

\section{The influence of rational thinking and cultural cognition on attitudes toward nudges}

Logistic regression analyses were conducted to explore the influence of individual differences on attitudes toward the presented nudge-policies. Table 2 shows the result from these analyses where the effects of individual differences on perceiving a nudge-policy as acceptable and intrusive to freedom of choice are presented as Odds Ratios (OR). In accordance with our prediction, respondents who scored high on the CCWVG-scale (i.e., respondents with a more individualistic worldview) were less likely to judge nudge-policies as acceptable i.e., Odds Ratio less than 1 . This effect of individualistic worldview was significant $(\mathrm{p}<.001)$ for all eight presented nudge-policies. The level of individualistic worldview did, however, not show any systematic effect on to what extent respondents viewed nudge-policies as intrusive to freedom of choice.

The pattern is somewhat different for the influence of preferences for analytical thinking on attitudes toward nudge-policies (see Table 2). For acceptability, differences in analytical thinking did not have any systematic influence on acceptance. For intrusiveness to freedom of choice, however, respondents who scored high on the REI-rational scale (i.e. respondents who 
have stronger preference for analytical thinking) were systematically less likely to judge nudge-policies as intrusive, compared to respondents who scored low on the REI-rational scale.

Table 2 shows that the higher rate of general acceptance seen in Sweden compared to the United States remains when taking individual differences (i.e. analytical thinking and individualistic worldview) and characteristics (i.e. gender, age, education) into account. Further, US subjects are more prone to judge nudge-policies as intrusive also when taking individual differences between samples into account.

Table 2. Logistic regression analyses exploring the influences of individual differences in "thinking and feeling" on attitudes toward nudge-policies (presented as Odds Ratios (OR))

\begin{tabular}{|c|c|c|c|c|c|c|c|c|c|c|c|c|c|c|c|}
\hline \multicolumn{16}{|c|}{ Acceptability } \\
\hline & \multicolumn{2}{|c|}{$\begin{array}{c}\text { Organ } \\
\text { Donation }\end{array}$} & \multicolumn{2}{|c|}{$\begin{array}{c}\text { Climate } \\
\text { compensation }\end{array}$} & $\begin{array}{l}\text { Avoiding } \\
\text { tax } \\
\text { evasion }\end{array}$ & \multicolumn{2}{|c|}{$\begin{array}{c}\text { Energy } \\
\text { consumption }\end{array}$} & \multicolumn{2}{|c|}{$\begin{array}{l}\text { Smoking } \\
\text { cessation }\end{array}$} & \multicolumn{2}{|c|}{$\begin{array}{c}\text { Smoking } \\
\text { discouragement }\end{array}$} & \multicolumn{2}{|c|}{ Cafeteria } & \multicolumn{2}{|c|}{$\begin{array}{c}\text { Food } \\
\text { labeling }\end{array}$} \\
\hline & OR & Sig & OR & Sig & OR Sig & OR & Sig & OR & Sig & OR & Sig & OR & Sig & OR & Sig \\
\hline Individualistic worldview $\left(\right.$ CCWVG) ${ }^{a}$ & 0.67 & ** & 0.60 & $* *$ & $0.66 * *$ & 0.70 & $* *$ & 0.73 & $* *$ & 0.68 & $* *$ & 0.64 & $* *$ & 0.77 & $*$ \\
\hline Analytical thinking (REI-rational) ${ }^{\mathrm{b}}$ & 0.98 & & 1.03 & & 1.01 & 1.02 & & 1.02 & & 0.93 & $*$ & 1.05 & & 1.00 & \\
\hline \multicolumn{16}{|l|}{ Country } \\
\hline Sweden & 2.60 & $* *$ & 1.91 & $* *$ & 1.04 & 1.05 & & 1.16 & & 2.29 & $* *$ & 1.36 & & 1.32 & \\
\hline USA & REF & & REF & & REF & REF & & REF & & REF & & REF & & REF & \\
\hline \multicolumn{16}{|l|}{ Gender } \\
\hline Female & 0.81 & & 1.21 & & 0.80 & 0.97 & & 0.85 & & 0.88 & & 1.16 & & 1.13 & \\
\hline Male & REF & & REF & & REF & REF & & REF & & REF & & REF & & REF & \\
\hline Age & 0.99 & & 0.99 & & 1.00 & 0.98 & $*$ & 0.96 & $* *$ & 0.99 & $*$ & 1.00 & & 1.00 & \\
\hline \multicolumn{16}{|l|}{ Education $^{c}$} \\
\hline Higher & 1.05 & & 1.22 & & 0.93 & 1.25 & & 1.17 & & 1.04 & & 0.99 & & 1.04 & \\
\hline Lower & REF & & REF & & REF & REF & & REF & & REF & & REF & & REF & \\
\hline \multicolumn{16}{|c|}{ Intrusiveness } \\
\hline${\text { Individualistic worldview }(C C W V G)^{a}}^{a}$ & 1.03 & & 1.15 & & 1.09 & 1.12 & & 1.08 & & 1.05 & & 1.16 & $*$ & 1.03 & \\
\hline Analytical thinking (REI-rational) ${ }^{\mathrm{b}}$ & 0.91 & $* *$ & 0.91 & $* *$ & $0.90 * *$ & 0.91 & $* *$ & 0.94 & * & 0.96 & $*$ & 0.93 & $* *$ & 0.94 & $*$ \\
\hline \multicolumn{16}{|l|}{ Country } \\
\hline Sweden & 0.76 & & 0.47 & ** & 0.74 & 1.61 & * & 0.84 & & 0.76 & & 0.97 & & 0.92 & \\
\hline USA & REF & & REF & & REF & REF & & REF & & REF & & REF & & REF & \\
\hline \multicolumn{16}{|l|}{ Gender } \\
\hline Female & 0.79 & & 0.62 & $*$ & 0.82 & 0.79 & & 0.77 & & 0.73 & $*$ & 0.92 & & 0.64 & $* *$ \\
\hline Male & REF & & REF & & REF & REF & & REF & & REF & & REF & & REF & \\
\hline Age & 1.00 & & 1.01 & & 1.00 & 1.00 & & 1.01 & $*$ & 1.00 & & 1.00 & & 0.99 & \\
\hline \multicolumn{16}{|l|}{ Education $^{c}$} \\
\hline Higher & 1.31 & & 0.93 & & 1.07 & 0.89 & & 0.87 & & 1.12 & & 1.08 & & 0.95 & \\
\hline Lower & REF & & REF & & REF & REF & & REF & & REF & & REF & & REF & \\
\hline
\end{tabular}

$\mathrm{p}<.05, * * \mathrm{p}<.001$

${ }^{\mathrm{a}}$ higher value on individualistic worldview (CCWVG) indicates a more individualistic worldview.

$\mathrm{b}$ higher value on Analytical thinking (REI-rational) indicates a stronger preferences for using analytic thinking.

${ }^{C}$ Education was categorized into higher (attended college or more, 64.4\%) or lower (High school or below, 35.6\%) education

\section{Discussion}

Behavioral measures that do not have public support are less likely to be successful. Hence it 
is important to understand when and why policies involving choice architecture are viewed as acceptable and when they are not. Moreover, a lack of public support may very well lead to adverse effects on the type of behavior it is trying to promote (see e.g. Bard 2012). This article provides previously lacking information on individuals' attitudes on public policies involving nudging. We also provide insights on how individual differences in thinking and feeling influence preference constructions related to policies involving nudges.

Overall there was a high level of stated support for policies involving nudges in both Sweden and USA across key policy areas. There was a majority support for all presented nudgepolicies included in the survey. Somewhat paradoxical, a majority of the respondents also judged the same policies as intrusive to freedom of choice in six out of eight scenarios.

This view is especially pronounced for policies that employ opt-out as a nudge mechanism. Consequently, many individuals seem to hold contradicting views or suffer from cognitive dissonance, highlighting the complexity of behavioral policy making. When comparing results between countries, support is generally higher in Sweden compared to United States. This difference in rate of acceptance is perhaps not surprising given that Sweden has had a longstanding tradition involving a strong welfare state emphasizing collective and uniform solutions throughout the public sector. While, in contrast, the political discourse in the United States has traditionally emphasized more liberal values related to freedom of choice. The difference between countries is also in accordance with previous studies that have found higher level of acceptability for state intervention on behavior in Sweden compared to the United States.

\section{Separating pro-social nudges from pro-self nudges}

In this article, we situate the missing category of pro-social nudges within the existing literature on nudges. Public policy ultimately seeks to promote social welfare. It is therefore natural that nudges are used to do just that. However, there are many situations where private welfare and social welfare diverge. In fact, for many of the most important areas of public policy it is profit maximizing for individuals to free ride and thereby refrain from cooperation and the type of prosocial behavior that typically is necessary to achieve a common societal goal. Pro-social nudges are non-coercive behavioral measures that encourage individuals to produce public goods and otherwise improve overall social welfare, even when doing so is inconsistent with maximizing private welfare. 
Within the framework of libertarian paternalism nudges have traditionally been viewed as interventions aimed at overcoming cognitive biases and decisional inadequacies of individuals, thus mainly targeting individuals' intuitive way of thinking. Normative objections related to a paternalistic state are less strong when focusing on nudges that aim to help individuals to overcome biases and move them toward decisions that they would make if having unlimited time, information and analytic capacity. However, as many of the problems we face today are collective (e.g. climate change), pro-social nudges are likely to become a more prominent policy tool in the future. When trying to influence individuals' rational thinking and steer them toward irrational behavior, the force of normative objections related to a paternalistic state are likely to gain strength. Consequently we expected nudges that were classified as pro-social to be viewed as less acceptable and more intrusive to individuals’ freedom of choice. Indeed this is also the result from the empirical survey. With this said it should be noted that the presented nudge scenarios vary along other dimensions in addition to whether they are pro-social or pro-self. Hence this study is not a strict experimental test on the distinction between pro-social and pro-self nudges. In future studies it would be interesting to test the distinction between pro-social and pro-self nudges in a setting where other dimensions are kept constant.

\section{Thinking and feeling in nudges}

The findings that both acceptability and perception of infringement on freedom of choice were systematically related to individual differences in worldviews and preference for analytic thinking adds to the common choice architecture framework by showing that individual factors, and not only information presentation, influences preference construction toward nudges. Overall, individuals high in individualistic worldview were less accepting of the different nudge-policies. This is directly in line with previous research on the effect of cultural cognition on attitudes to public policy (Kahan, 2006), but extend this finding to nudge interventions.

Our results showed that individual differences in analytical thinking did not have any systematic influence on acceptability. However, individuals with a preference for analytical thinking were systematically less likely to judge nudge-policies as intrusive to freedom of choice. The differential effect of world-views vs. thinking styles on acceptance and autonomy suggests that concept of “one-nudge-fits-all” is not tenable. Instead, people will judge acceptability and the moral implications of a behavioral intervention systematically 
differently depending on who they are. Thus, acceptance and autonomy in choice will not only depend on how information is presented (the typical behavioral intervention), but to whom the information is presented.

Recent writings on nudge theory have speculated that system 1 (feelings, intuitions) vs. system 2 (thoughts, reasoned analysis) processes both are central for nudge behaviors (Sunstein, 2014). For instance, engaging System 2 analysis may be a way to counter System 1 impulses leading to myopic decision behavior (e.g. not saving for retirement). Default nudges (e.g. automatically deducting a certain amount of money from the salary each month to a retirement account) may be a way to counter system 1 preference for immediate rewards. Our results suggest that individual differences in preference for analytic thinking systematically influenced perceptions of autonomy. However, the extent of the effect of individual differences likely depends on the extent to which the nudge-policy relies on System 1 or System 2 information processing (Epstein et al., 1996). Currently, a characterization of the nudges in terms of main mode of information processing is lacking. Future research should more carefully examine individual (preference for analytic thinking) x situational (mode of processing elicited by the nudge information) interactions. Such information is central for creating nudge-policies that are accepted and not seen as infringements of free choice.

While many of the effects of individual differences were comparable in Sweden and United States, some systematic differences emerged, suggesting that also cultural differences are important for acceptability of nudges. Recognizing that both individual and cultural factors will influence the perception of nudges is an important aspect both for successfully implementing nudges as well as nuancing nudge theory. Our findings are preliminary in the sense that we only included a few facets of individual differences. Future research should more exhaustively examine individual and cultural differences in acceptability of nudges. 


\section{Conclusions}

This is the first study that has explored public attitudes toward specific nudge-policies. Overall the results indicate a high level of support for policies involving nudges in both Sweden and the United States across key policy areas. Somewhat paradoxical a majority of the respondents also judged many of the same nudge-policies as intrusive to freedom of choice.

We situate the missing category of pro-social nudges within the existing literature on nudges. Pro-social nudges are non-coercive behavioral measures that encourage individuals to produce public goods and otherwise improve overall social welfare, even when doing so is inconsistent with maximizing private welfare. Pro-social nudges, however, do not fit into the paradigm of libertarian paternalism since private welfare is always maximized by not contributing to the common good. In this survey nudge-polices classified as pro-social were found to have a significantly lower acceptance rate compared to nudge-policies classified as pro-self.

Exploring individual differences in "thinking and feeling” we found that differences in worldview and preference for analytic thinking were systematically related to attitudes toward nudge-policies. Specifically we found that individuals with a more pronounced individualistic worldview were less accepting of nudge-policies, and individuals with a preference for analytical thinking were less likely to judge nudge-policies as intrusive to freedom of choice. To conclude, our findings suggest that the notion of "one-nudge-fits-all” is not tenable. Recognizing this is an important aspect both for successfully implementing nudges as well as nuancing nudge theory. 


\section{References}

Amir, O. and Lobel, O. (2008) Stumble, predict, nudge: How behavioral economics informs law and policy. Columbia Law Review 108: 2098-2137.

Bard, J. (2012) Lack of political will and public trust dooms presumed consent. The American Journal of Bioethics Volume 12(2), 44-46.

Bovens, L. (2009) The ethics of nudge. In T. Grüne-Yanoff and S.O Hansson (Eds.), Preference change: approaches from philosophy, economics and psychology, Dordrecht: Springer

Branson, C. Duffy, B. Perry, C. and Wellings, D. (2011) Acceptable behaviour? Public opinion on behaviour change policy. Ipsos Social Research Institute

Epstein, S. Pacini, R. Denes-Raj, V. and Heier, H. (1996) Individual differences in intuitiveexperiential and analytical-rational thinking styles. Journal of Personality and Social Psychology 71: 390-405.

Frederick, S. (2005) Cognitive reflection and decision making. Journal of Economic Perspectives 19(4): 25-42.

Hardin, G. (1968) The Tragedy of the Commons, Science, 162: 1243-1248.

Hausman, D. M. and Welch B. (2010) To nudge or not to nudge? The Journal of Political Philosophy:18(1), 123-136.

Johnson, E. J. and Goldstein, D. (2003) Do defaults save lives? Science, 302: 1338-1339.

Kahan, D. M. (2006) Cultural cognition and public policy. Yale Law and Policy Review, 24:147-170.

Kahan, D. M. Braman, D. Cohen, G. L. Gastil, J. and Slovic, P. (2010) Who fears the HPV vaccine, who doesn't, and why? An experimental study of the mechanisms of cultural cognition. Law and human behavior, 34(6): 501-516.

Kahan, D. M. (2014) Cultural cognition as a conception of the cultural theory of risk. In S. Roeser (Ed.), Handbook of risk theory, Dordrecht: Springer.

Kahneman, D. (2011) Thinking, fast and slow. New York: Farrar, Straus and Giroux.

Kemmelmeier, M. (2009) Authoritarianism and its relationship with intuitive-experiential cognitive style and heuristic processing. Personality and Individual Differences, 48: 44-48.

Norris, P. Pacini, R. and Epstein, S. (1998) The Rational-Experiential Inventory, short form. University of Massachusetts at Amherst. 
Marteau, T. M. Ogilvie, D. Roland, M. Suhrcke, M. and Kelly M. P. (2011) Judging nudging: can nudging improve population health? BMJ 342:228.

Pedhazur, E. J. (1997) Multiple Regression in Behavioral Research (3rd ed.). Orlando, FL:Harcourt Brace.

Peters, E. and Slovic, P. (1996) The role of affect and worldviews as orienting dispositions in the perception and acceptance of nuclear Power. Journal of Applied Social Psychology, 26(16): 1427-1453.

Slovic, P. (1995) The construction of preference. American Psychologist, 50: 364-371.

Sunstein, C. R. (2014) Why nudge? The politics of libertarian paternalism, New Haven: Yale University Press.

Stanovich, K. E. and West, R. F. (2000) Individual Differences in Reasoning: Implications for the Rationality Debate, Behavioral and Brain Sciences 23: 645-665.

Thaler, R. H. and Benartzi, S. (2004) Save More Tomorrow: Using behavioral economics to ncrease employee saving, Journal of Political Economy 12(1), 164-187.

Thaler, R. H. and Sunstein, C. R. (2008) Nudge: Improving Decisions about Health, Wealth and Happiness, New Haven: Yale University Press. 